\title{
DA SALA À PRAÇA: MOTIVAÇÃo, MEDIAÇÃo E VIGOTSKY PARA ENTENDER O COMPORTAMENTO
}

\author{
Cláudio Márcio Magalhães
}

\begin{abstract}
Resumo
A motivação é tema chave para a disciplina de Comportamento do Consumidor nos cursos de Publicidade e Propaganda. Mas sua conceituação é abordada por diversas teorias, por vezes contraditórias. Soma-se a aversão do alunato quanto ao estudo teórico. Esse trabalho propõe uma abordagem que o leve a construir seu próprio entendimento, sem menosprezar os diferentes do seu. Desenvolveu-se uma série de atividades, entre tradicionais e inovadoras, através uma metodologia ativa, que considere o aluno o centro de sua formação. Como referência, o psicólogo e educador Lev Vigotsky. Espera-se que sirva de incentivo para metodologias semelhantes, que unam o ambiente escolar com o espaço público, o interior da sala com o interior do sujeito.
\end{abstract}

PALAVRAS-CHAVE

Comunicação social; grade curricular; graduação; publicidade e propaganda; Vigotsky

\begin{abstract}
Motivation is a key subject for the discipline of Consumer Behavior in Advertising and Propaganda courses, despite the fact that its conceptualization is approached by several theories that may sometimes be contradictory in addition to alumni aversion to the theoretical study. This work proposes an approach that leads one to build one's own understanding, without underestimating different perspectives. A series of activities were developed ranging from traditional to innovative by means of an active methodology, which considers the student the center of his or her own learning. As a reference, the research was based on the work of the Russian psychologist and educator Lev Vigotsky in an attempt to become an incentive for similar methodologies that link the school environment with the public space, the interior of the classroom with the subject's interior.
\end{abstract}

\section{KeYwORDS}

Advertising and propaganda; curricular framework; social communication; university graduation course; Vigotsky

O próprio aluno se educa (Vigotsky, 2001, p. 448)

\section{INTRODUÇÃo}

Este trabalho defende o uso de uma metodologia ativa para a compreensão do estudante de Publicidade e Propaganda sobre Motivação, algo que cada vez mais tem sido presente nos cursos superiores no Brasil. Inicialmente nas graduações da área de saúde, tais metodologias agora se estendem às demais áreas de conhecimento. Embora possa 
ter uma aparência de inovação, trata-se de um retorno a uma pedagogia, bastante debatida no século $X X$, que propõe o deslocamento do protagonismo da educação formal das mãos exclusivas do professor em direção a um aluno enquanto sujeito de sua própria aprendizagem (Araújo, 2015; Borges \& Alencar, 2014; Diesel, Baldez \& Martins, 2017).

$\mathrm{Na}$ área da Comunicação Social, as metodologias também se integram quase que organicamente. De acordo com Carniello e Zulietti (2015), as áreas das Ciências Sociais Aplicadas, onde se integram a Comunicação Social e suas habilitações (entre elas a Publicidade e Propaganda), já fazem uso de metodologias que privilegiam a prática, sob o marco teórico de Paulo Freire (Meditsch, 2004). Assim, metodologias de ensino da formação do profissional da comunicação incorporam métodos hoje associados às metodologias ativas, como o PBL - Problem Based Learning (vindo da área da saúde): "tais métodos, dadas as suas especificidades, têm em comum o dato de serem centradas no ser humano" (Carniello \& Zulietti, 2015, p. 279).

Tal iniciativa deve-se a um incômodo que o professor pesquisador encontrou ao ministrar a disciplina Comportamento do Consumidor: a de que, em um curso de Comunicação Social, são poucas as oportunidades dos alunos entenderem como, antes de consumidores, somos sujeitos em busca de respostas, que nos sentimos condicionados, angustiados, humanos, aprendizes e educadores/educandos. E que, mesmo após milhões de anos de evolução cultural, ainda assim continuamos a nos perguntar quem somos, o que somos e porque somos assim.

Seria a disciplina de Comportamento do Consumidor uma oportunidade de utilizar uma abordagem menos positivista sobre o sujeito do consumo, sobre a publicidade e sobre os próprios estudantes? Ao trazer os alunos para o centro de sua aprendizagem, poder-se-ia trazer visões distintas de comportamento e motivação, que influenciaram historicamente a publicidade, mas de forma que se complementassem? Ao tratar da base do comportamento, a motivação, tal eixo poderia ser também a motriz desta iniciativa?

Tais questionamentos, restritos aos cursos com ênfase na psicologia, não deveriam passar ao largo das análises do público-alvo da publicidade. Afinal, o consumo, enquanto comportamento, é manifestação do que nos compõe como ser humano complexo, fluido e inesperado, mas, ao mesmo tempo, desafiador e excitante. O curso de Publicidade e Propaganda deve dar um tempo no olhar para fora, para o mercado, a sociedade, o contexto, e dar uma olhada para dentro, tentando entender, afinal, porque compro essa blusa se, ainda assim, mantenho sentimentos dúbios pela atitude (culpa, prazer, satisfação, angústia).

O relato a seguir é sobre uma série de atividades que tinham como objetivo auxiliar estudantes de graduação a entender um dos mistérios que permeia a existência humana: o que nos move? Era necessário, primeiro, que os alunos entendessem as principais teorias que, de alguma forma, influenciaram o entendimento da publicidade sobre a temática. E, segundo, a de que nenhuma delas dá conta de explicar como e o porquê esse sujeito assim se comporta, em casa, na rua, no shopping.

Como embasamento teórico, em especial, Lev Vigotsky, para quem, em 1926, já defendia que 
até hoje o aluno tem permanecido nos ombros do professor. Tem visto tudo com os olhos dele e julgado tudo com a mente dele. Já é hora de colocar o aluno sobre as suas próprias pernas, de fazê-lo andar e cair, sofre dor e contusões e escolher a direção. (Vigotsky, 2001, p. 452)'

Portanto, o apelo por uma metodologia ativa, que coloque o aluno no centro de sua aprendizagem, já não é de hoje, mas ainda permanece como exceção na prática educativa. Assim, este trabalho tem ciência que não é uma proposta de vanguarda, já que o pensamento de Vigostky é amplamente desenvolvido e utilizado, e que vários outros pensadores, contemporâneos e posteriores a sua obra, também tratam desta abordagem, como se verá adiante. Mas nunca é demais reforçar a convicção de insistir em sua idealização, desenvolvimento, sistematização, aplicação e avaliação. O sonho de Vigotsky ainda é o de boa parte dos educadores.

Esse artigo se constitui de sete partes: essa introdução, em seguida a descrição da necessidade da disciplina de Comportamento do Consumidor no curso de Publicidade e Propaganda, as colaborações buscadas em Vigotsky, uma abordagem sobre motivação e a descrição das atividades da metodologia proposta. Ao final, uma pequena análise de resultados que, porventura, não foram descritas na parte anterior, seguida das conclusões.

\section{DESENVOLVENDO ENTENDIMENTOS SOBRE A MOTIVAÇÃo}

\section{Porquê entender de teoria do comportamento em Publicidade e Propaganda}

No primeiro dia de aula, há um esclarecimento: do ponto de vista do professor, há duas maneiras de ministrar a disciplina Comportamento do Consumidor. A primeira remete à longa tradição do marketing, a partir dos anos 1970 no Brasil, de chamar para si toda a responsabilidade de um negócio e que teve no economista norte-americano, Philip Kotler, seu principal expoente. O clássico Marketing (Kotler, 1980) foi uma importante referência, dado que deu origem a um sem número de novas edições, publicações com atualizações, além de continuadores de suas premissas em inúmeras outras obras. Seu sucesso deve-se ao aprofundamento nas minúcias de um negócio, dividindo em partes cada vez menores e, a partir deste exame apurado, estabelecer estratégias e encontrar soluções.

O consumidor, portanto, é visto como mais uma engrenagem que, mesmo sendo ponto central do objetivo de marketing, ainda assim é uma peça a ser compreendida enquanto item instrumental para a máquina de consumo continuar funcionando. Em si, essa abordagem não é um problema e, de fato, ajuda a ter uma visão sistematizada do

\footnotetext{
' Ressalta-se que a obra de Vigotsky, pensador russo falecido em 1934, tem grande distância entre sua concepção e o seu uso contemporâneo, e certamente não tratou da educação superior nos moldes do século XXI. No entanto, o seu resgate, que começa nos anos 1960', segue influenciando as visões sobre aprendizagem em todos os segmentos da educação, dada sua profundidade no que tange a mediação e o papel do interacionismo simbólico e os seus aspectos culturais e históricos, de origem marxista, mas no qual tem importante avanço. Seu avanço na educação superior ainda é tímido na literatura brasileira, mas pesquisadores cada vez mais se utilizam de seus pensamentos para encontrar soluções (Oliveira \& Pôrto, 2014; Werlang, Machado, Shihadeh \& da Motta, 2012).
} 
negócio e, com isso, instrumentar os profissionais que pensam, planejam, implantam e analisam produtos e serviços. Portanto, nada contra a abordagem do marketing com o consumidor.

No entanto, como apontado por Pinto e Lara (2008), em um estudo que analisou 238 artigos sobre o que se publicou no Brasil sobre o comportamento do consumidor, há uma supremacia de trabalhos com abordagem empírica, positivista e o uso de metodologias quantitativas. Os autores relatam a entrada de escolas de perspectivas não interativas e econômicas no debate do tema como evolução, mas que não tem sido suficiente para a mudança nos profissionais. Sugerem, ao final do estudo, justamente a ampliação de uso de diferentes metodologias, inclusive nas instituições de ensino, que valorizem o fenômeno e a interpretação.

Segundo os autores, "não seria hora de se propor novas abordagens de cunho fenomenológico ou interpretativista, a fim de se investigar melhor o comportamento dos consumidores a partir de outra perspectiva?" (Pinto \& Lara, 2008, p. 98). Estes pesquisadores acreditam que é preciso fugir do processo linear e estático do estudo do comportamento do consumidor, privilegiando conflitos, diversidade e multidisciplinaridade.

No entanto, particularmente no curso de Publicidade e Propaganda, sentia-se falta de falar mais das pessoas, coadjuvantes nas diversas disciplinas instrumentalistas ou de análise crítica aos meios e da sociedade da informação. Ambos eixos importantes, mas que conduziam o olhar dos estudantes de si para fora, desconstruído o que é externo, para analisar, fazer ou reelaborar.

São capacidades e habilidades fundantes de um bom profissional. Mas faltava o olhar para dentro. Afinal, antes de engrenagem, somos homens e mulheres com partes um tanto complexas para se pegar e analisar como uma roldana: inconsciente, alma, espírito, estilo, angústias, impulsos, experiências, sentimentos, memórias afetivas e sensoriais.... A lista é enorme.

A Publicidade e Propaganda, ao longo de sua história, não se negou a isso e também andou se perguntando como somos movidos, com o intuito de ensinar aos publicitários como fazer a melhor peça publicitária que fizesse mover o seu público para o produto, o serviço, a ideia que tentava seduzir. Mas as referências teóricas foram mudando com o tempo, a cada nova leva de publicitários e pesquisadores insatisfeitos por não conseguirem entender seus consumidores. No entanto, cada onda de influência deixou marcas e referências que ainda repercutem no discurso dos publicitários e clientes (Sant'anna, Rocha Júnior \& Garcia, 2016; Strocchi, 2007).

Portanto, os discursos que os futuros publicitários irão encontrar pela frente, na sua carreira profissional e no trato da temática do comportamento do consumidor, serão permeados das referências da psicologia. Segundo Sant'anna, Rocha Júnior e Garcia (2016), alguns conceitos da psicologia foram e são fundamentais para as técnicas publicitárias: motivação, desejo, emoção, imaginação, inibição, interesse, percepção, associação de ideias, entre outras.

Já sobre estudos do comportamento do consumidor, Karsaklian aponta que são uma ciência aplicada vinda das ciências humanas e sociais, envolvendo a economia, a 
sociologia, a antropologia e a psicologia: "no início, os pesquisadores pensavam utilizar todas as ciências envolvidas com a mesma intensidade, porém pode-se observar que a mais utilizada é a psicologia" (2008, p. 20).

Assim, no início das atividades, quando os estudantes assistem ao primeiro episódio da série de ficção Mad Men, que trata do mundo das agências de publicidade icônicas dos anos 1950 nos Estados Unidos - e que vai acompanhar as décadas seguintes ao longo das demais temporadas -, já são expostos ao dilema do publicitário angustiado que não encontra mais respostas no seu jeito de interpretar o seu consumidor de cigarro.
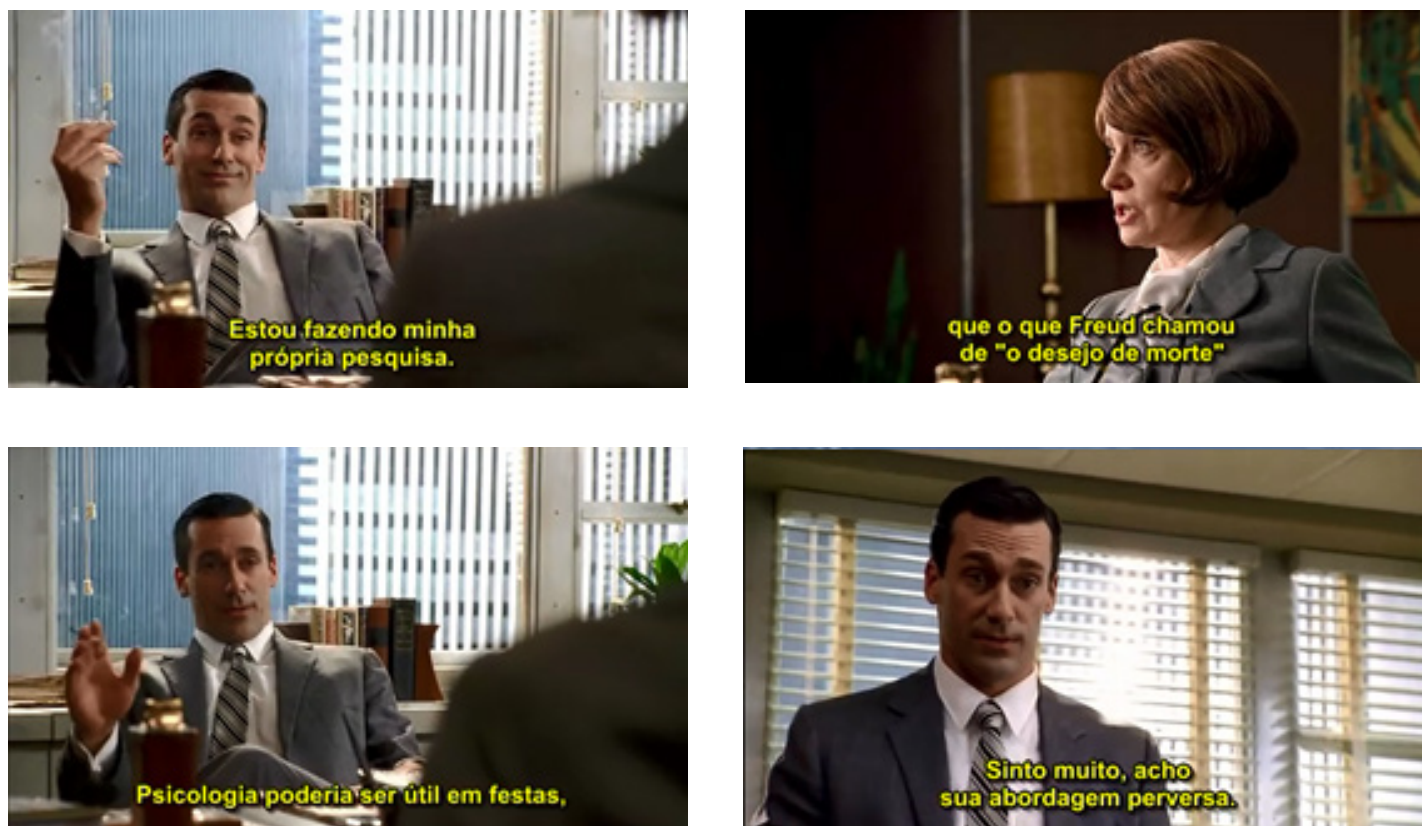

Figuras 1 a 4: Cenas de Mad Men: o publicitário behaviorista Don Draper debate com a psicanalítica e pesquisadora Greta Guttman

Fonte: Lions Gate Entertainment (2007), Mad Men - Episódio 1 - 13:20-15:40

Don Draper, o anti-herói da série, um behaviorista clássico, não consegue perceber que suas referências de como pensar o consumidor não lhe dão mais respostas, e resiste bastante a repensar. Assim, quando em um diálogo com uma psicanalítica pesquisadora - a psicanálise irá dominar as referências publicitárias nas décadas seguintes - mesmo desprezando as ideias de sua interlocutora, a acusa de ter uma abordagem perversa. Sem perceber, Don Draper já usa uma referência da psicanálise, mostrando que já está, sem o notar, fazendo sua transição (Figuras 1 a 4).

Ora, se o executivo mais vistoso de uma agência é incapaz de dizer da onde vem seu discurso, o que dirá o futuro chefe dos futuros publicitários e seus clientes? Por outro lado, a efemeridade das teorias, somada à sua incapacidade de dar uma resposta definitiva à questão de saber como consumimos e, principalmente, porquê, deve obrigar ao futuro profissional a manter a mente aberta a todas as referências, tanto para que ele não seja dominado por apenas uma, se tornando um seguidor de uma espécie de 
ideologia científica - algo que parece acometer a Don Draper -, para que possa entender seus colegas, profissionais e clientes, sem que os classifique como errados ou alienados apenas por pensarem o ser humano de uma caixa distinta.

\section{Metodologias ATIVAS De Vigotski}

Embora as metodologias ativas estejam, merecidamente, entrando nas atividades escolares com cada vez mais frequência, aqui se entende que é o êxito de uma militância que não é deste século. E nem do anterior. John Dewey já defendia a experiência como o melhor professor, e que caberia ao educador ser um mediador do processo (Dewey, 2011). A lista de personalidades preocupadas com o foco no conteúdo na educação formal, sugerindo que o educando fosse a fonte principal de seu próprio conhecimento, ajudado pelo professor, mas não oprimido por ele, não é pequena e nem de hoje. Além de Dewey (2007), Maria Montessori (1965), Adolphe Ferrière (1928), Célestin Freinet (2001), Jean Piaget (1998), Anísio Teixeira (2007), Paulo Freire (2015), são apenas alguns que já pensavam em metodologias ativas com propriedade e convicção².

Lev Vigotsky também acredita que o melhor papel a ser feito pelo professor é o de mediação. Sua descrição da Zona de Desenvolvimento Imediato (ZDI), mais conhecida no Brasil com Zona de Desenvolvimento Proximal, por um erro de tradução (Bezerra, 2000), reforçou a impressão de diversos educadores de que a criança não é uma tábua rasa, que ela tem um nível intelectual anterior a educação formal, e que é capaz de entender o seu meio, tomar posição, ter razoabilidade e tomar iniciativas, e até a fazer coisas sozinhas onde antes precisava de ajuda: não podemos ignorar a circunstância de que a aprendizagem escolar nunca começa no vazio mas sempre se baseia em determinado estágio do desenvolvimento, percorrido pela criança antes de ingressar na escola (Vigotsky, 2001, p. 476). Embora Vigotsky fale das crianças, certamente pode-se pensar nos estudantes em qualquer momento de sua vida acadêmica, inclusive entrando na universidade como explorado por diversos pesquisadores (Borges \& Alencar, 2014; Diesel et al., 2017; Trigo, 2016).

E isso, de forma alguma, diminui ou menospreza o papel do professor. Só que o muda radicalmente. Vigostsky escreve, no início do século $X X$, cheio de esperanças que de aquele mestre como "simples fonte de conhecimento, de livro ou de dicionário de consulta, manual ou demonstrador, em suma, [que] atua como recurso auxiliar e instrumento de educação" (Vigotsky, 2001, p. 447) já estava condenado. O que escreve em seguida bem poderia ser o retrato do início do século XXI:

atualmente, esse papel vem sendo cada vez mais reduzido a zero e substituído de todas as maneiras pela energia ativa do aluno, que em toda a parte deve não viver do alimento que o mestre lhe fornece mas procurar por conta própria e obter conhecimentos, mesmo quando os recebe do mestre.

\footnotetext{
${ }^{2}$ Sabe-se que a obra dessa/es autora/es é vasta e a temática está em mais de uma publicação. Aqui se apontou apenas uma delas como sugestão de introdução.
} 
Já nos livramos daquele preconceito segundo o qual o mestre deve educar. Estamos igualmente distantes dessa concepção, como o estamos daquela segundo a qual o homem deve carregar o seu fardo nos próprios ombros. (Vigotsky, 2001, p. 447)

Vigotsky tem sido resgatado por pesquisadores que querem realçar o professor como mediador (Meier \& Garcia, 2007). Mas, para o infortúnio da educação, nada garante que, daqui cem anos, novos pesquisadores também nos chamem de sonhadores, caso continue prevalecendo a cobrança por professores apenas pela memorização de conteúdos. O que não impede, como neste e em muitos outros casos, o professor de tentar.

\section{EM BUSCA DO ENTENDIMENTO DO QUE É A MOTIVAÇÃo}

Um dos tópicos mais importantes da disciplina Comportamento do Consumidor, na abordagem descrita anteriormente, é o entendimento do que seja Motivação. É um daqueles conceitos que parece que todos conhecem, mas têm dificuldades ao tentar explicar. É confundido com impulso (que é uma ação proveniente a motivação), com incentivo (que é algo externo a nós), com instrumentos e referências sociais, como dinheiro, emprego, família (Karsaklian, 2008).

"A complexidade dos motivos do homem é maior do que a possibilidade de explicá-los mediante alguma teoria biológica dos seus impulsos" (Burton, 1978, p. 16). Na realidade, desde que o homem desenvolveu consciência, ele se pergunta o que o move. As respostas já foram, e são, entre uma entidade mística superior até uma programação interna também com diferentes ideias, entre um inconsciente inatingível até um determinado cromossomo.

Mesmo quando pensamos que "motivo" seja "uma condição interna relativamente duradoura que leva o indivíduo ou que o predispõe a persistir num comportamento orientado para um objetivo, possibilitando a transformação ou a permanência de situação" e a motivação "o processo que produz tais condições" (Sawrey \& Telford, 1973, p. 18), ainda parece uma explicação insegura. Afinal, que condições seriam essas?

A disciplina parte do princípio de que não existe um conceito definitivo de motivação. Que o profissional irá se deparar com vários conceitos, alguns convergentes, outros conflitantes. E que, como a humanidade ainda não se decidiu qual é o definitivo, todos eles abarcam contribuições e deficiências, típicas dos construtos sociais.

Aqui importa saber quais são as explicações, os pontos de vista, as abordagens que a publicidade, ao longo de sua curta história, tem se apropriado e agregado ao seu discurso. E quais são as contaminações que esses conceitos fazem no cotidiano, a ponto de povoarem as falas e as interpretações das pessoas quando pensam em motivação.

O inegociável, no entanto, é que tudo parte de uma motivação. Essa condição é o estopim para todas as demais etapas que levam a um comportamento: necessidade, desejo, percepção, atitudes. A escolha por essa descrição de comportamento, um tanto linear, é inspirada nas teorias cognitivas comportamentais, que também ajudam o marketing. Sua escolha, portanto, deve-se a tentativa de não se distanciar demais da área 
mercadológica, embora queira torná-la mais complexa ao introduzir questões de uma psicologia mais aprofundada.

Como se vê, o objetivo da disciplina, como um todo, não é negar as abordagens mais empíricas, mas trazê-las a luz de uma interpretação mais diversificada, complexa. Neste sentido, busca-se desenvolver no aluno competências para compreender diferentes formas de entender a origem da motivação e suas consequências, e analisar essas visões dentro de um determinado problema de comunicação. Desenvolvendo habilidades como classificar, definir, identificar como as pesquisas, seu público e si mesmo têm perspectivas sobre essa (e outras) temáticas, será capaz de discutir, mensurar, avaliar, escolher formas de resolução baseadas em uma conjunção de fatores dinâmicos, que leve em conta desde o empírico, o social e a psique.

Certamente, tal abordagem foge da tradição continuísta de difusão de informação como conhecimento, e alguns problemas na mudança dos paradigmas didático-pedagógicos das escolas, mas é algo que tem sido incorporado às escolas com rapidez. Assim, o primeiro movimento com os estudantes, baseado em Vigostky é entender de onde partem os estudantes quando se pensa em motivação. É uma fala libertadora. Se, em milhões de anos, a humanidade ainda não entrou em acordo sobre o que é motivação, o que o aluno pensa que é pode não estar nem completamente certo ou errado. O que se deve deixar claro é que, qualquer que seja a explicação, é herança de alguém que pensou sobre isso antes.

Portanto, a trajetória que se pretendeu dar às aulas parte deste primeiro ponto, o de onde o aluno está. Em seguida, usando de mediação do professor, aliado a instrumentos pedagógicos ou adaptados para isso, vai-se tentando trazer elementos conceituais que vão fazendo sentido. Por fim, é necessário ir a campo, testar as hipóteses, através da observação participante, e experimentar o conhecimento em uma situação real. Para concluir, conversar sobre processos e resultados. As atividades foram divididas em etapas, descritas em conjunto com seus resultados, a fim de um acompanhamento mais próximo do leitor sobre a metodologia.

\section{DESCRIÇÃo DAS ETAPAS}

\section{O QUE É MOTIVAÇÃo PELOS ALUNOS: PLATAFORMA POLLEVERYWHERE}

Vigotsky vai defender uma teoria do interesse, para que o educador possa se conectar com o seu estudante:

A regra psicológica básica de elaboração de interesse é a seguinte: para que o objeto nos interesse, ele deve estar vinculado a alguma coisa do nosso interesse, algo já conhecido, e ao mesmo tempo deve conter algumas formas novas de atividade, senão continuará sem dar resultados. (Vigotsky, 2001, p. 115)

Neste sentido, na primeira aula, ao invés de dar uma explanação sobre os diversos conceitos de motivação, buscou-se saber dos alunos o que essa palavra significava para 
eles. No entanto, ao invés de abrir para as tradicionais mãos levantadas, solicitou-se que todos usassem seus aparelhos celulares para se manifestar. Essa era a nova forma de atividade, uma alternativa ao modelo tradicional, e que também quebrava a impressão de que o professor vê os aparelhos de telefonia apenas como um concorrente desleal.

Aqueles que não tinham aparelhos capazes de acessar a internet, eram convidados a participar dos colegas. Foi solicitado, então, que entrassem na plataforma PollEveryWhere ${ }^{3}$, que permite vários usuários enviarem conteúdo escrito e, ao mesmo tempo, responder a perguntas. Como não é preciso que os estudantes se cadastrem, façam login (apenas o professor precisa), é rápida a participação. Como atrativo adjacente, aqueles alunos que, em geral, não gostam ou se intimidam de participar de um debate aberto, nesta ferramenta podem se manifestar, já que os usuários permanecem anônimos.

O resultado é, então, projetado na tela do datashow (Figura 5). Assim, aos poucos, os estudantes foram respondendo à questão "o que é motivação?" tendo como limite o uso de apenas uma palavra, aquela que mais sintetizasse uma opinião (afinal, é um curso de publicidade, onde a síntese é uma capacidade a ser alcançada e uma habilidade a ser construída). Inicialmente, todos podiam ir vendo as palavras, enquanto o professor as repetia em voz alta, elogiando a participação e se mostrando entusiasmado com a variedade e a pertinência das respostas.

Em seguida, com os alunos ainda empolgados, interessados, após o uso inusitado dos celulares, o professor acionou uma das ferramentas da plataforma para conseguir uma nuvem de tags, ou seja, uma representação gráfica das palavras mais recorrentes que, à medida que eram repetidas, cresciam em tamanho (Figura 6).
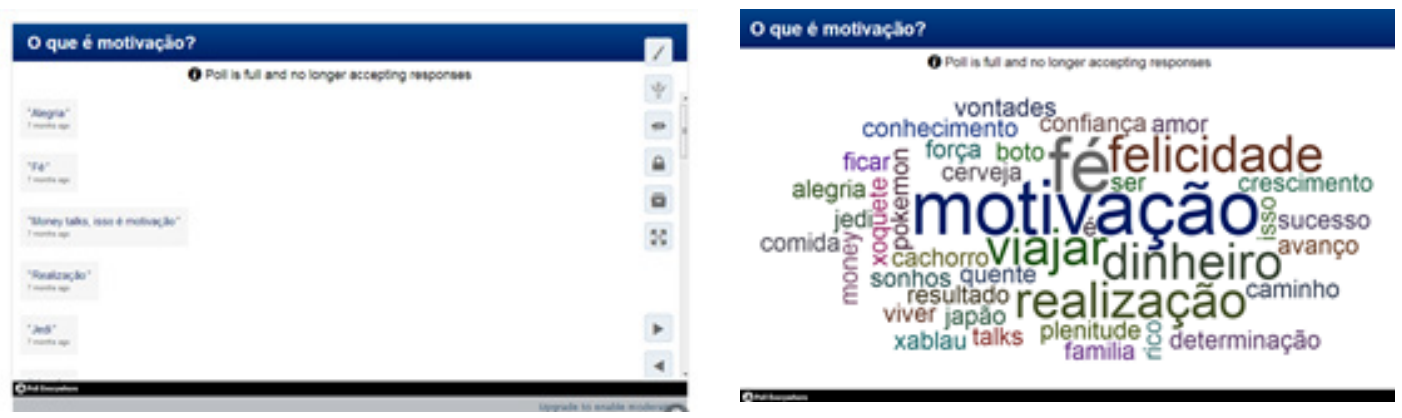

Figuras 5 e 6: Respostas dos alunos projetadas na tela

O professor aproveitou do resultado para, primeiro, mostrar que a sua construção era coletiva e, de alguma maneira, representava o entendimento prévio daquela turma sobre motivações. Em seguida, mostrou que, embora a palavra dinheiro tivesse tido algum destaque, boa parte do que saltou aos olhos eram coisas sem tangibilidade, de difícil conceituação, embora de relativo fácil entendimento: felicidade, fé, realização, viajar são expressões que todos entendem com rapidez e, neste sentido, o coletivo consegue decifrar. No entanto, as palavras teriam um significado próprio para cada um, dentro da

${ }_{3}$ Disponível em https://www.polleverywhere.com/ 
sua história, da sua percepção do mundo do, então, nível intelectual e da experiência social anterior àquela atividade.

Portanto, como conclusão dessa atividade, ficou a ideia de que não seria muito fácil conceituar motivação.

\section{Algumas Motivações: aula expositiva e revista Galileu}

É criado o incômodo. Afinal, a universidade deveria ser o lugar onde aprender os conceitos mais importantes para a carreira, e as demais disciplinas têm demonstrado isso, quando se sabe o melhor enquadramento de uma foto em uma peça publicitária, as cores que melhor se harmonizam, as estratégias vencedoras das grandes marcas. Como assim, não teremos um conceito de motivação?

Está claro para qualquer um que quanto mais forte é o incômodo que dá o primeiro impulso ao movimento da alma tanto mais forte é o próprio movimento, que a educação e a criação são sempre trágicas porque partem do "incômodo" e do mal-estar, da desarmonia. (...) A música da educação surge de uma dissonância que ela procura resolver. (Vigotsky, 2001, p. 461)

Neste momento, é importante o professor oferecer a mão, ajudar a entender o incômodo e oferecer algo que o deixe mais confortável, que o deixe menos perdido. A aula expositiva clássica não é o oposto da metodologia ativa, e nem a anula. Ao contrário, é parte integrante de um processo integrado de pedagogias e didáticas.

Nesse sentido, finalmente se introduzem os textos teóricos sobre a temática da motivação, a partir do livro base da disciplina (Karsaklian, 2008). No entanto, para trazer uma nova forma de aprendizagem, acrescenta-se, com a mesma importância, uma reportagem de capa da revista Galileu (Tonon, 2011). A publicação tem como objetivo uma divulgação científica com uma linguagem mais leve, coloquial, voltada para o público jovem, mas sem perder sua característica de ser uma publicação voltada para a ciência.

Com um texto claramente não acadêmico, nos moldes que assim são conhecidos, a intenção é desmistificar que a ciência objetiva só é encontrada nos livros específicos da academia. Destes textos, é retirada a aula expositiva dialogada - haja vista que permeada por questionamentos aos alunos de exemplos da vida pessoal ou do cotidiano que podem ilustrar o dito pelo professor e pelos textos. Em resumo, após esclarecer que outros autores definem um número diferente, mas não distante das premissas, se apresenta quatro elementos motivacionais.

São eles nossa busca pela autonomia, pelo conhecimento, pela vida dinâmica e pelo engajamento. O dinheiro, que aparece nas falas iniciais dos alunos, é elemento importante, não por si só, mas como instrumento mediador para se alcançar o que se busca. Para exemplificar, o chamamento aos estudantes é se recordarem de sua infância. Assim, é possível lembrar como as crianças se esforçam para fazer coisas sozinhas - mesmo quando não conseguem; como se encantam em aprender - obcecadas por pequenas coisas como insetos e inundando os adultos de porquês; gostam de estar com 
outros, brincar em conjunto, sem discriminações raciais, étnicas e de gênero; e raramente têm dúvidas dos seus propósitos, ou concentradas na sua atividade, ou correndo em direção dela.

Munidos dos quatro motivos, são também convidados a se expressarem. Fazem o curso de publicidade para atender a qual? Qual deles hoje foi o principal motivo de olharem para as atividades do dia que se segue? Só se atende um de cada vez, ou pode ser o conjunto de dois ou mais? É possível analisar o comportamento do consumidor usando essas referências? ${ }^{4}$

Tal abordagem na sala retorna à ZDI de Vigotsky. É certo que nem todos pensam como ele, mas aqui se concorda que o desenvolvimento das funções psíquicas superiores passa por duas etapas. Vigotsky vai tratar da criança, mas, como dito anteriormente, não há porque não pensar nos alunos da graduação5. "A primeira como atividade coletiva, social, ou seja, como função interpsíquica; a segunda, como atividade individual, como modo interior de pensamento da criança, como função intrapsíquica" (Vigotsky, 2001, p. 483):

um exemplo do desenvolvimento do discurso pode servir de paradigma a todo o problema nesse sentido. O discurso surge inicialmente como meio de comunicação entre a criança e as pessoas que a rodeiam. Só posteriormente, ao transformar-se em discurso interior, ele se torna modo fundamental de pensamento da própria criança, função psíquica interior. (Vigotsky, 2001, p. 483)

Portanto, coube ao professor apresentar um discurso inicial, fruto de um aparato técnico anterior (os textos), colocá-los ao coletivo, mediando com exemplos práticos e metáforas - que são construtos também sociais, e, por fim, deixar que cada um leve as perguntas do parágrafo anterior a dialogar consigo mesmo.

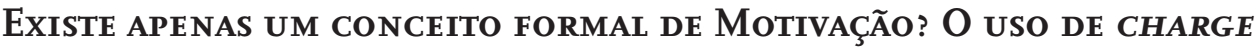

Depois de uma pausa para descomplicar a temática, é o momento de retornar novamente aos questionamentos. Neste sentido, a classe é convidada a analisar uma charge onde duas mulheres se acusam mutuamente, em pensamento, de comportarem-se, pelo consumo de suas roupas, para atender a "uma cultura machista, cruel e dominadora" (Figura 7). Uma está vestida com uma burca, traje oriental que oculta todo o corpo, outra de biquíni.

\footnotetext{
${ }_{4}^{4}$ Este seria um momento também para o uso da metodologia de análise de discurso, mas o tempo escasso para a sua realização impossibilitou a investigação. No entanto, seria uma importante continuidade e/ou proposta de nova abordagem.

${ }_{5}^{5}$ Vigotsky contesta, inclusive, o psicólogo e filósofo norte-americano Willian James (1842-1910). "A concepção de James, segundo quem depois dos vinte e cinco anos os adultos não podem adquirir novas ideias, acaba sendo desmentida no curso das investigações experimentais modernas. Entretanto, até hoje, não foi suficientemente esclarecido o que difere basicamente a aprendizagem dos adultos da aprendizagem da criança" (Vigotsky, 2001, pp. 484-485).
} 


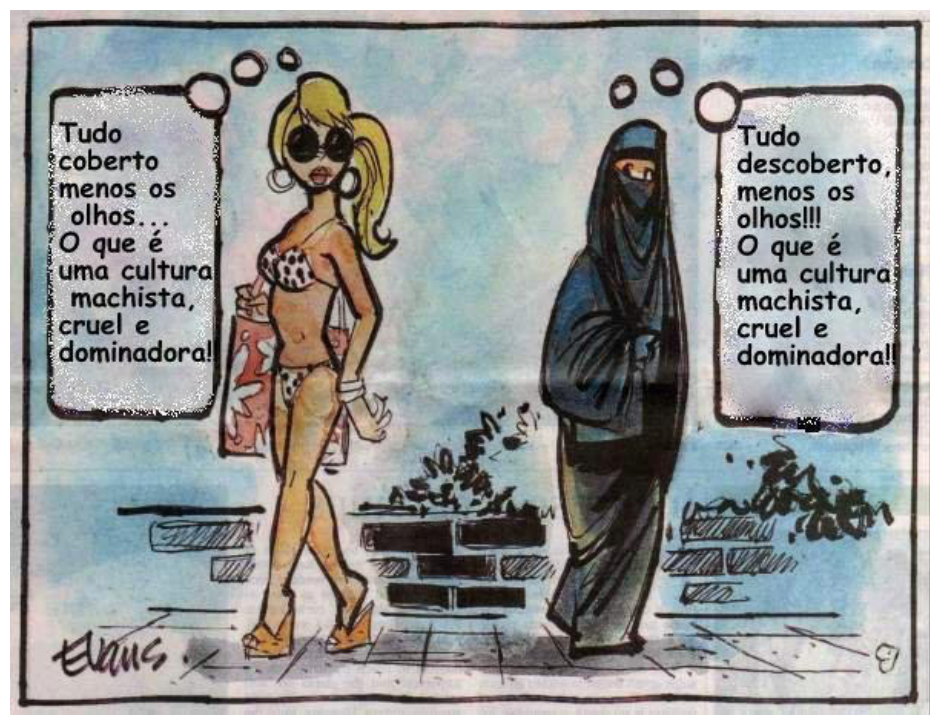

Figura 7: Charge que questiona o discurso e seu ponto de vista

Fonte: charge de Malcolm Evans (data e tradução desconhecidas)

A discussão que se segue à exibição da charge se mostra rica. A argumentação não se restringe ao fato mais explícito da ilustração, o de que pode ter-se visões de mundo completamente distintas usando-se o mesmo discurso. O debate fica acalorado, pois sempre alguém lembra que a charge pode estar relegando a questão da liberdade, que a mulher de burca não a teria, enquanto que a outra sim. É preciso pouca intervenção do professor, pois há outro/a que defende que essa é uma limitada visão ocidental da cultura oriental, e que muitas se vestem assim, não porque são obrigadas, mas porque acreditam e defendem o uso daquela vestimenta.

Embora aconteça em outros momentos, nesta etapa aparece uma das principais qualidades de uma metodologia ativa: o diálogo. Segundo Cunha,

há princípios que nos devem aderir à alma, ou quiçá dela fazerem já parte: como o de sempre termos obrigação de dialogar; e o diálogo, muitas vezes parecendo de surdos, traz quase sempre novos ângulos para os nossos pontos. Não é pois totalmente desperdiçada a polémica, mesmo com quem seria preciso tentar colmatar muitas lacunas, de dados e de interpretações. Não tanto pelo efeito que a nossa palavra possa fazer no interlocutor, mas pela variedade de surpresa de argumentos, quantos deles sem pertinência, mas que alargam os horizontes, e, no limite, fazem entender a Humanidade. Ou para tanto vão dando achegas. (Cunha, 2016, p. 248)

O debate, portanto, caminha para questões como opressão machista oriental, que tiraria o livre-arbítrio e a informação sobre direitos da mulher e, assim, ela não teria opção, inconsciente ou conscientemente, sobre sua condição. Outro/a lembra da questão européia, onde mulheres muçulmanas estão lutando pelo direito de usar véu, proibido em diversas regiões. Então, o fazem por uma questão cultural e de fé. E, finalmente, chega-se a um impasse quando outro/a lembra que a mulher de biquini pode até não ter 
toda essa liberdade, pois também pode-se pensar que se veste assim para atender um modelo de mulher da qual ela não tem como fugir, caso queira se considerar relevante e desejável, duas características caras da cultura ocidental.

Portanto, o que se conclui é que não se pode fechar a questão, que ambas as visões de mundo estão com razão, do seu ponto de vista, mas que também podem estar utilizando um discurso que reflete uma teoria sobre relações de gênero, impregnada na cultura e nas próprias mulheres. Se tem o gancho para entrar para a próxima fase.

\section{UMA TEORIA MOTIVACIONAL PARA CHAMAR DE SUA: OS SEMINÁRIOS}

Assim, a partir da conclusão da atividade anterior, os estudantes estão prontos a não pensar que existe uma teoria que dê conta de tudo que envolve o comportamento de consumo. Mas é possível ver a teoria no cotidiano do publicitário e, melhor, o confrontamento delas como aconteceu na charge?

É aí que entra a exibição dos primeiros 15 minutos do primeiro episódio de Mad Men. Os minutos iniciais, além de apresentarem os principais personagens, e suas características mais marcantes de personalidade, mostra a angústia do anti-herói principal em criar mais uma campanha publicitária, e sua indisposição, tanto com sua atual maneira de pensar, behaviorista, como de tentar entender outro ponto de vista (psicanalítico), conforme a cena descrita anteriormente. Acrescenta-se que, naqueles minutos, ainda se desenha um quadro altamente machista daquela sociedade, que causa grande estranhamento hoje, mas que comprova que os discursos estão condicionados à sua cultura e temporalidade, como no embate da charge.

Portanto, após abrir para o debate na sala sobre o vídeo e os incômodos causados, é hora de preparar os seminários onde as linhas teóricas de comportamento serão apresentadas. Com duas delas já tiveram algum contato: behaviorismo e psicanálise. As demais, cognitiva, humanista e evolucionista, são apresentadas brevemente. Em seguida, o professor faz uma provocação: todas essas teorias são facilmente achadas na internet e nos livros do plano de aula. Portanto, não caberá ao professor dar aulas sobre elas. Os alunos o farão para toda a turma, em grupos de teorias que eles, inicialmente, escolhem por afinidade inicial da abordagem de cada conceito.

A turma se divide e definem-se os grupos. Em seguida, é passada a tarefa (Figura 8) e a agenda da apresentação.

Os alunos são lembrados que fazem um curso onde a estética é parte integrante da linguagem profissional e, portanto, devem apresentar slides atrativos e informativos, como em uma apresentação a um cliente. De fato, boa parte dos grupos faz apresentações elaboradas (Figura 9 e 10) e a estratégia de descolar a responsabilidade das aulas para os alunos traz três diferenciais em relação à aula tradicional dada pelo professor: o primeiro, o de tornar quem apresenta, os protagonistas das aulas, responsáveis pelo conteúdo - o que, em sua maioria, foi assumido de forma séria. O segundo é estético, pois os slides são muito mais bonitos e atrativos. E o terceiro é revelar ao professor aspectos das teorias que, porventura, havia relevado anteriormente e agora se percebe 
que são questões de interesse, ou que o professor acreditava terem impacto nos alunos e são por eles minimizados.

\section{ESTUDO DIRIGIDO 1 una}

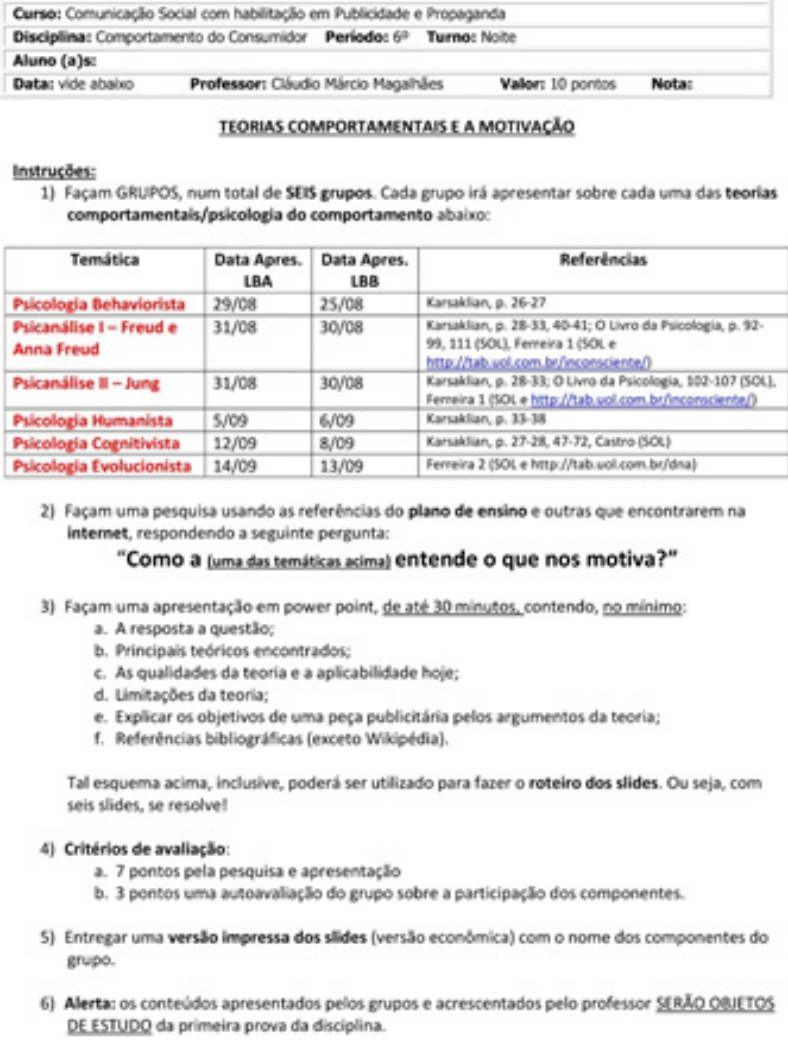

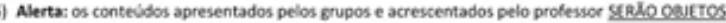
DE ESTUDO da primeira prova da dicciplina.

Figura 8: Orientações para o seminário de teorias comportamentais
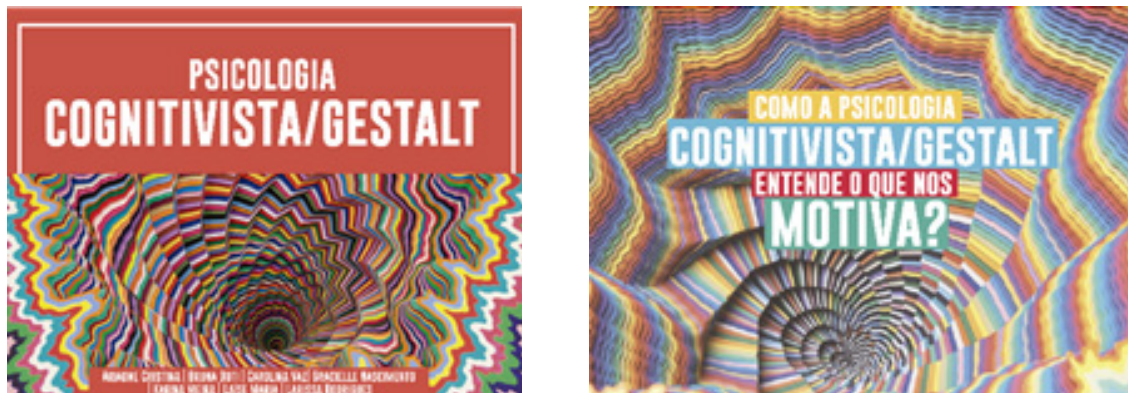

Figura 9 e 10: Slides de apresentação de um grupo no seminário

O professor, após a apresentação de um grupo, faz três movimentos: o primeiro, elogia o grupo, pede uma salva de palmas e pergunta como eles se sentiram produzindo o material. Em seguida, reforça algumas informações que o grupo apresentou, no sentido de alertar os demais de que aquelas questões são fundamentais, escrevendo no 
quadro algumas palavras-chave pelo grupo e que ajudaram a fixar a teoria. E, por fim, o professor acrescenta conteúdos que, porventura, tenham ficado de fora da apresentação.

Ao final, as aulas teóricas, que, geralmente, têm, pelos alunos, uma reputação de entediantes, acabam por serem ministradas pelos próprios alunos para os seus colegas. No entanto, sabe-se que tal metodologia, a de seminários ofertados pelos alunos, não é nova e é algo usado com certa frequência. Mas ela é necessária para o que é a fase derradeira.

\section{As teorias MotivaCionais IN LOCo: UM PASSEIO PELA PRAÇA}

Vigotsky vai criticar os métodos tradicionais de estudos de conceitos. O que fizemos anteriormente lhe pareceria "mais um estudo do produto que do processo que leva à formação do produto" (Vigotsky, 2000, p. 151). Para o psicólogo russo, a palavra não pode ser exclusivista, pois o conceito

está vinculado ao material sensorial de cuja percepção e elaboração ele surge; o material sensorial e a palavra são partes indispensáveis do processo de formação dos conceitos e a palavra, dissociada desse material, transfira todo o processo da definição do conceito para o plano puramente verbal. (...) O essencial mesmo para o conceito - a sua relação com a realidade fica aí sem ser estudado. (Vigotsky, 2000, p. 152)

Portanto, era necessário levar a palavra à praça. Literalmente. Foi proposto, então, um segundo exercício, mas agora em grupos menores de, no máximo, quatro alunos. $O$ trabalho em grupo tinha a intenção da troca de ideias e consolidação dos conhecimentos, sempre mais efetivos quando em diálogo, principalmente de conceitos muitas vezes fluidos.

Assim, a tarefa (Figuras 11 e 12) agora era ir a uma praça, observar alguém consumindo alguma coisa e, daí, fazer uma análise do seu significado a partir das concepções, pontos de vista, de cada teoria da motivação. Seria preciso consultar suas anotações, conversar com os colegas, relembrar as palavras-chave, ou seja, era preciso dar sentido às palavras antes escutadas e/ou lidas. E consolidava-se a ideia principal de que é possível olhar para o mesmo fenômeno com diversos olhares e essa seria uma fundamental habilidade do publicitário ao pensar sobre o consumidor.

As experiências foram trazidas para a sala de aula, para que relatassem o processo, como se sentiram na abordagem, os casos curiosos de apropriação da praça e as formas de consumo inusitadas ou impensadas anteriormente. Além de uma lista maior de possibilidades de motivações que as levaram para aquele espaço público. 


\section{ESTUDO DIRIGIDO 2}

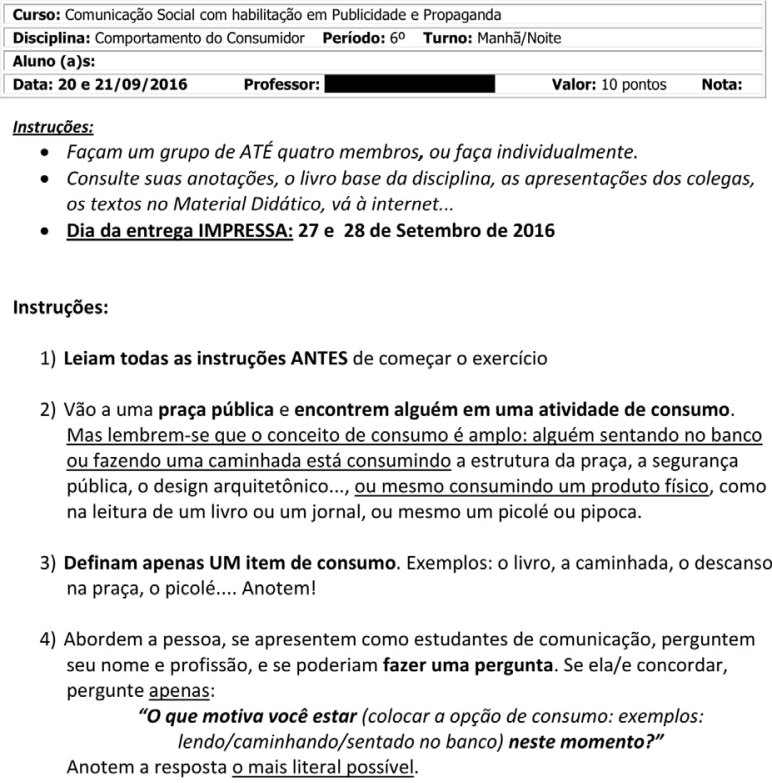

1) Leiam todas as instruções ANTES de começar o exercício

2) Vão a uma praça pública e encontrem alguém em uma atividade de consumo. Mas lembrem-se que o conceito de consumo é amplo: alguém sentando no banco ou fazendo uma caminhada está consumindo a estrutura da praça, a segurança pública, o design arquitetônico..., ou mesmo consumindo um produto físico, como na leitura de um livro ou um jornal, ou mesmo um picolé ou pipoca.

3) Definam apenas UM item de consumo. Exemplos: o livro, a caminhada, o descanso na praça, o picolé.... Anotem!

4) Abordem a pessoa, se apresentem como estudantes de comunicação, perguntem seu nome e profissão, e se poderiam fazer uma pergunta. Se ela/e concordar, pergunte apenas:

O que motiva você estar (colocar a opção de consumo: exemplos: lendo/caminhando/sentado no banco) neste momento?" Anotem a resposta o mais literal possivel.

5) Peçam licença para tirar uma fotografia dela/e na atividade de consumo. Atenção: façam o possível para que não seja uma foto posada, e solicite que ela fique o mais natural possivel, repetindo o momento como era ANTES de ser abordada/0 por vocês. Agradeçam e façam uma despedida.

6) Façam um relatório como no exemplo a seguir:

\section{ESTUDO DIRIGIDO 2}

Curso: Comunicação Social com habilitação em Publicidade e Propaganda Disciplina: Comportamento do Consumidor Período: $6^{\circ}$ Turno: Manhã/Noite Aluta (a)s:
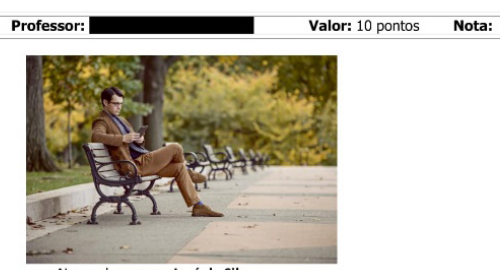

Nome da pessoa: José da Silva Ato de consumo: Lendo um livro

"O que motiva você estar_lendo__ neste momento?

Como vocês acreditam que cada escola que estudou as motivações comportamentais
explicaria essa resposta? Mas não se baseiem apenas nas respostas, mas também na explicaria essa resposta? Mas não se baseiem apenas nas respostas, mas também na
percepção de vocês de todo o contexto onde está inserida a atividade de consumo:

\begin{tabular}{|l|l|}
\hline Behavioristas & \\
\hline Psicanalistas & \\
\hline Humanistas & \\
\hline Cognitivistas & \\
\hline Evolucionistas & \\
\hline
\end{tabular}

Figuras 11 e 12: Orientações para o seminário de teorias comportamentais 
Os alunos abordaram os mais simples usos (Figuras 13 a 15).
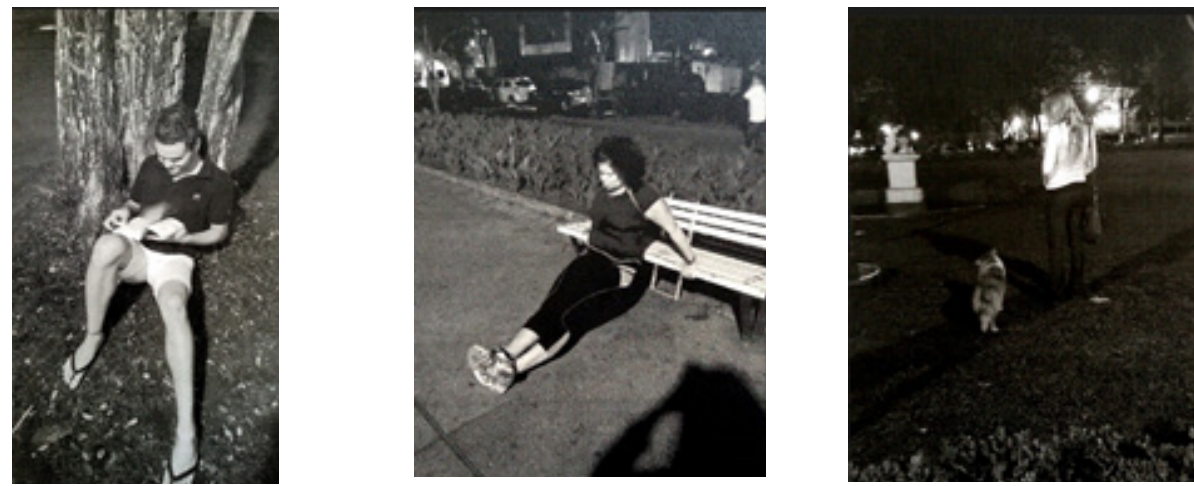

Figuras 13, 14 e 15: Fotografias dos usuários da Praça da Liberdade/BH em consumo

Mas certamente encontraram aqueles que usam para atividades artísticas e corporais, em grupo ou solitariamente (Figuras 16 a 18), e situações inusitadas, como o casal que vai para tomar conta dos cachorros de outros, na impossibilidade de tê-los em sua própria casa (Figura 19).
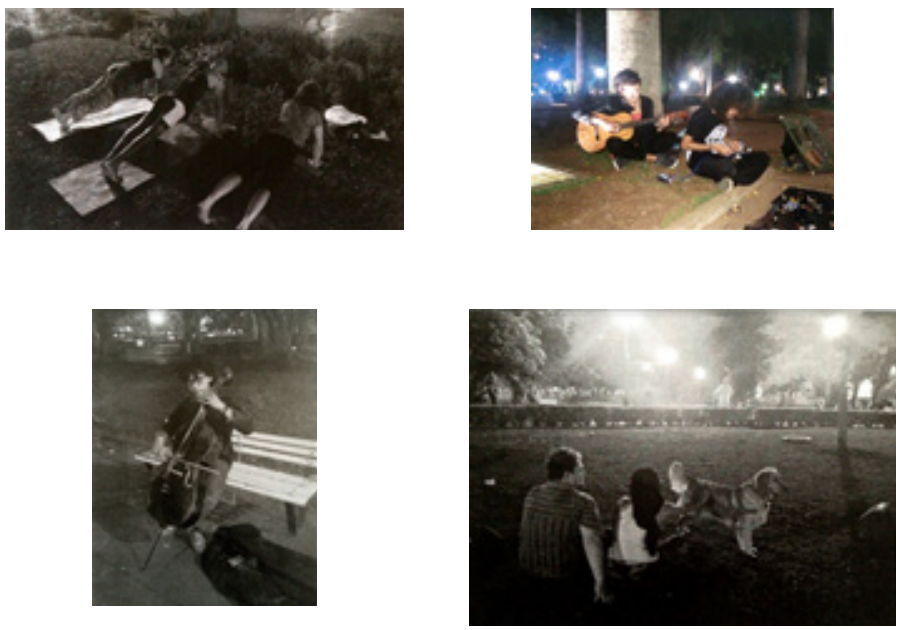

Figuras 16, 17, 18 e 19: Fotografias dos usuários da Praça da Liberdade/BH em consumo

No mesmo lugar onde se encontram pessoas que utilizam o espaço para se enamorarem (Figura 20), também um grupo se deparou um casal que estava ali para terminar o relacionamento (Figura 21). 

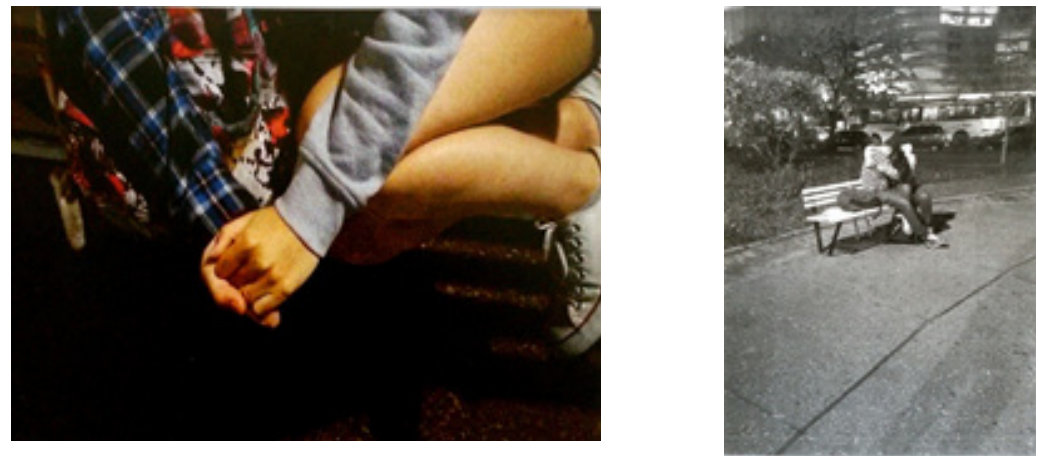

Figuras 20 e 21: Enquanto um casal usa a praça para namorar, outro usa para se separar

A atividade, portanto, rendeu uma série de experiências onde a palavra, pesquisada e colocada aos colegas, é escutada por eles, postas à prova e à praça, gerando relatos que serviram para o momento final.

No encerramento, os relatórios serviram para que o professor voltasse às temáticas, fizesse comparações, dialogasse sobre o consumo como algo muito além do que uma troca financeira, e relembrasse que cada teoria contribui, de alguma maneira, tanto para um discurso sobre o consumo, como para entender um modo de vida. E que um profissional de comunicação pode até escolher uma dessas visões de mundo, do que nos motiva, como sua. Mas, agora, saberia que há outros olhares e eles não são necessariamente equivocados.

Por fim, o professor convidou os estudantes a fazerem mais isso, a olhar o mundo com a complacência e a tolerância da miríade de possibilidades do que nos faz mover, do que nos motiva. Uma delas pode estar até certa, mas não precisamos obrigatoriamente de saber. Apenas entender.

\section{ConCLUsões}

Os principais resultados foram sendo descritos ao longo do documento. Essa opção deve-se a uma tentativa de dar maior sentido e fluidez ao texto, até mesmo para levar o leitor àqueles momentos de compartilhamento e mediação do e com o professor.

Há ainda um resultado a ser mencionado. A disciplina tem um momento, por volta da metade de seu curso, onde o professor aplica uma prova de múltipla escolha, semeIhante às aplicadas pelo Exame Nacional de Avaliação do Ensino Superior (ENADE). Esse tipo de avaliação, além de cumprir a determinação de notas exigidas pela escola, também procura mensurar o quanto caminha a classe quanto à aquisição do conhecimento. E também serve para ir treinando o estudante para esse tipo de prova, que também encontrará em concursos e exames de seleção.

A partir de um banco de questões que possibilita fazer provas diferentes a cada semestre, mas que seguem uma certa uniformidade, permite-se comparar turmas diferentes. Valendo 20 pontos, antes da aplicação das atividades aqui descritas, os estudantes nunca alcançaram 50\% das notas. Após a aplicação, já alcançaram a média exigida pela escola. Houve um aumento de mais de $25 \%$. Essa prova tem uma grande participação 
do conteúdo sobre motivação, já que ocupa uma parte considerável do primeiro semestre, embora não seja exclusiva no exame. No entanto, esse dado estatístico tem pouca importância para esse trabalho, com caráter qualitativo. Mesmo porque o fazer uma prova congrega outras vieses de interpretação que aqui não se dá conta de abordar. É apenas um indicativo, mas não definitivo.

Em retrospecto, ao sistematizar o trabalho feito, se apercebeu de alguns pontos a aprimorar.

Os resultados dos relatórios poderiam ter sido também sistematizados e levados à turma para uma nova análise coletiva. Embora o professor tenha ratificado de que o que importava era o caminho percorrido e não o resultado final, uma correção coletiva, talvez um grupo dando parecer sobre o relatório do outro, seria mais um momento de aprendizagem e reforço ao conhecimento. Em atividades posteriores, foi solicitado aos grupos da realização de mapas conceituais, em resultados ainda a serem mensurados.

Boa parte dos trabalhos foi feito à mão, o que impediu de fazer uma nova nuvem de tags e, assim, reforçar, uma vez mais, as palavras-chave de cada teoria. A qualidade estética e artística das fotos também surpreendeu e poder-se-ia ter feito uma exposição no hall da escola, sociabilizando ainda mais o conhecimento. Como sugestão de novos trabalhos, uma análise do discurso dos estudantes tem o potencial de novas descobertas e usos pedagógicos, em vários momentos, tanto analisando o discurso dos estudantes como dos consumidores.

Vigotsky é referência pelos motivos sistematicamente descritos neste texto, mas pode ser resumido na sua concepção de pensar o aluno num sujeito carregado pelo social e, portanto, apto a considerá-lo o principal agente de sua própria aprendizagem.

Dentro desta concepção, cabe ao professor o papel de moderador e aos instrumentos e técnicas pedagógicas o de facilitadores desta prática. No entanto, essa não é uma tarefa simples, perante resistências de todas as ordens, desde as práticas escolares tradicionais, algumas institucionalizadas e não deixando autonomia ao educador, passando pelo estranhamento dos estudantes e até relutâncias naturais do próprio professor, cada vez mais atarefado e sem tempo para testar inovações.

Esse trabalho não busca ser um manual fechado da aplicação das metodologias aqui demonstradas, mas um convite a extrapolar as práticas, primeiro nas disciplinas de Comportamento do Consumidor, mas também em outras temáticas que, porventura, tenham abertura para diversas abordagens teóricas, na esperança de possíveis adaptações ou apenas como inspiração.

\section{REFERÊNCIAS BIBLIOGRÁFICAS}

Araújo, J. C. S. (2015) Fundamentos da metodologia de ensino ativa (1890-1931). In Anais $37^{a}$ Reunião Nacional da ANPEd. Florianópolis: UNIUBE/UFU.

Bezerra, P. (2000). Prólogo do tradutor. In L. S. Vigotsky, A construção do pensamento e da linguagem (pp. VIIXIV). São Paulo: Martins Fontes. 
Borges, T. S. \& Alencar, G. (2014). Metodologias ativas na promoção da formação crítica do estudante: o uso das metodologias ativas como recurso didático na formação crítica do estudante do ensino superior. Cairu em Revista, 3(4), 119-143.

Burton, A. (1978). Teorias operacionais da personalidade. Rio de Janeiro: Imago.

Carniello, M. F. \& Zulietti, L. F. (2015). Métodos pedagógicos em cursos de comunicação social: aplicação e formação de banco de casos. Unopar Científica Ciências Humanas e Educação, 16(4), 278-289. doi: $10.17921 / 2447-8733.2015 \mathrm{v} 16 n 4 p 278-289$

Cunha, P. F. (2016). Do direito à educação e da sua circunstância: reflexões sobre educação em democracia e seus obstáculos. Revista Lusófona de Estudos Culturais/Lusophone Journal of Cultural Studies, 3(2), 239-260.

Dewey, J. (2007). Democracia e educação - capítulos essenciais. São Paulo: Ática.

Dewey, J. (2011). Experiência e educação. Petrópolis: Vozes.

Diesel, A. Baldez, A. L. S. \& Martins, S. N. (2017). Os princípios das metodologias ativas de ensino: uma abordagem teórica. Thema, 14(1), 268-288. doi: 10.15536/thema.14.2017.268-288.404

Ferrière, A. (1928). Transformemos a escola. Apelo aos pais e às autoridades. Paris: Livraria Francesa e Estrangeira.

Freinet, C. (2001). Para uma escola do povo. São Paulo: Martins Fontes, SP.

Freire, P. (2015). Pedagogia da autonomia: saberes necessários à prática educativa. Rio de Janeiro: Paz e Terra.

Karsaklian, E. (2008). Comportamento do consumidor. São Paulo: Atlas.

Kotler, P. (1980). Marketing. São Paulo: Atlas.

Medistsch, E. (2004). A formação para a praxis profissional do jornalista: uma experiência brasileira inspirada em Paulo Freire. Comunicação e Sociedade, 5(1), 25-38. doi: 10.17231/comsoc.5(2004).1243

Meier, M. \& Garcia, S. (2007). Mediação da aprendizagem: contribuições de Feuerstein e de Vygotsky. Curitiba: Edição do Autor.

Montessori, M. T. A. (1965). Pedagogia científica: a descoberta da criança. São Paulo: Editora Flamboyant.

Oliveira, K. K. F. \& Pôrto, C. M. V., (2014). Comunicação entre acadêmicos surdos e ouvintes na mediação da aprendizagem no ensino superior. Cadernos de Terapia Ocupacional da UFSCar, 22(2), 335-345. doi: $10.4322 /$ cto.2014.055

Piaget, J. (1998). Psicologia e pedagogia: a resposta do grande psicólogo aos problemas do ensino. Rio de Janeiro: Forense Universitária.

Pinto, M. R. \& Lara, J. E. (2008). O que se publica sobre comportamento do consumidor no Brasil, afinal? Revista da Administração UFSM, I(1), 85-100. doi: 10.5937/2177-6652/2017.v17i2.1146

Sant'anna, A., Rocha Júnior, I. \& Garcia, L. F. D. (2016). Propaganda: teoria, técnica e prática. São Paulo: Cengage Learning.

Sawrey, J. M. \& Telford, C. W. (1973). Psicologia educacional. Rio de Janeiro: Ao Livro Técnico.

Strocchi, M. C. (2007). Psicologia da comunicação: manual para o estudo da linguagem publicitária e das técnicas de venda. São Paulo: Paulus. 
Teixeira, A. (2007). Educação não é privilégio. Rio de Janeiro: UFRJ.

Tonon, R. (2011). O que nos motiva? Galileu, 239, 35-43. Retirado de http://revistagalileu.globo.com/Revista/ Common/O,,EMl236569-17773,00-O+QUE+NOS+MOTIVA.html

Trigo, I. M. F. (2016). O curso de artes visuais do PARFOR-UNEB: breves notas sobre a importância das políticas educativas participativas. Revista Lusófona de Estudos Culturais/Lusophone Journal of Cultural Studies, 3(2), 283-296.

Vigotsky, L. S. (2000). A construção do pensamento e da linguagem. São Paulo: Martins Fontes.

Vigotsky, L. S. (2001). Psicologia pedagógica. São Paulo: Martins Fontes.

Werlang, R. B., Machado, F. O., Shihadeh, H. L. \& da Motta, L.F. (2012). Análise da inserção da teoria sociointeracionista em atividades de laboratório de física básica em um curso de geofísica. Caderno Brasileiro de Ensino de Física, 29(2), 246-266. doi: 10.5007/2015-7941

\section{OUTRAS REFER̂̂NCIAS}

Lions Gate Entertainment (2007), Mad Men - Episódio 1. DVD, Universal Pictures, Mad Men Season 1-6

\section{Nota BiográficA}

Cláudio Márcio Magalhães é professor e orientador do Programa de Pós-Graduação em Gestão Social, Educação e Desenvolvimento Local e do Instituto de Comunicação e Artes do Centro Universitário Una. Ministra disciplinas como Uso de Tecnologia em Gestão Social e Educação, Metodologia e Comportamento do Consumidor e, além dessas áreas, se dedica ao estudo da mídia e infância, sendo autor de Os programas infantis da TV: teoria e prática para entender a televisão feita para as crianças. Jornalista, mestre em Comunicação Social, doutor em Educação, pela Univervidade Federal de Minas Gerais.

Email: claudiomagalhaes@uol.com.br

Morada: Rua Wilson Modesto Ribeiro, 155/1005 - Ipiranga - Belo Horizonte - MG $-31.16-430-$ Brasil

\section{* Submetido: 24.08.2017}

* Aceite: 15.03 .2018 